\title{
Comparative Histological Study of Atherosclerotic Lesions and Microvascular Changes in Amputated Lower Limbs of Diabetic and Non-Diabetic Patients
}

\begin{abstract}
Objetive: To perform a comparative analysis of atherosclerotic lesions and capillaries changes in diabetic and nondiabetic patients. Methods: Leg arteries and skin of 57 amputated lower limbs of diabetic $(47.3 \%)$ and nondiabetic patients were histologically examined. The percentage of arterial stenosis of infrapopliteal arteries and the histological classification of atherosclerotic lesions were determined. Capillary thickening was classified into four categories. Results: Diabetic group showed more than $75 \%$ stenosis in $57 \%$ (vs. $56 \%$ in nondiabetic) of the anterior tibial; $78 \%$ (vs. $68 \%$ ) of the posterior tibial; $58 \%$ (vs. $50 \%$ ) of the peroneal leg arteries. Diabetic and nondiabetic patients have predominance of type $\mathrm{VI}$ atherosclerotic lesions. The comparison of both groups showed no significant differences in atherosclerotic lesions. Diabetic patients had significantly more PAS positive capillary thickening (63\% vs. $23 \%$ ). Conclusions: There were no differences in histological characteristics of atherosclerosis between the two groups. Capillary thickening has been more observed in diabetics. (Arq Bras Endocrinol Metab 2008; 52/7:1115-1123)
\end{abstract}

Keywords: Diabetes mellitus; Atherosclerosis; Lower extremity; Diabetic angiopathies; Diabetes complications

\section{RESUMO}

Estudo Histológico Comparativo das Lesões Ateroscleróticas e Alterações Microvasculares em Membros Inferiores Amputados de Pacientes Diabéticos e Não-diabéticos.

Objetivo: Comparar as lesões ateroscleróticas das extremidades de diabéticos e não-diabéticos, estudando a ocorrência de espessamento capilar. Métodos: Examinou-se segmentos arteriais e da derme de 57 membros inferiores amputados de diabéticos $(47,3 \%)$ e não-diabéticos. Analisou-se a porcentagem de estenose das artérias infra-poplíteas e a classificação histológica da placa. A presença de espessamento capilar foi classificada em quatro categorias. Resultados: Entre os diabéticos $57 \%$ (versus $56 \%$ dos não-diabéticos) apresentavam estenose maior que $75 \%$ da artéria tibial anterior; $78 \%$ (versus $68 \%$ ) da tibial posterior; $58 \%$ (versus $50 \%$ ) da fibular. Houve predominância em ambos de lesões ateroscleróticas do tipo VI. Comparando os grupos, não houve diferença significante na porcentagem de obstrução arterial ou na classificação da placa aterosclerótica. Os diabéticos apresentaram significativamente mais espessamento capilar $(63 \%$ versus 23\%). Conclusões: Não houve diferença nas características das lesões ateroscleróticas em diabéticos e não-diabéticos. $O$ espessamento capilar foi mais prevalente entre os diabéticos. (Arq Bras Endocrinol Metab 2008; 52/7:1115-1123)

Descritores: Diabetes melito; Aterosclerose; Extremidade inferior; Angiopatias diabéticas; Complicações do diabetes original

\author{
Vanessa Prado dos Santos \\ Roberto Augusto Caffaro \\ Geanete Pozzan \\ Mauro ajaj SaIEg \\ Valter Castelli JÚNIOR
}

Vascular Surgery, School of Medical Sciences, Santa Casa de São Paulo, São Paulo, SP, Brazil (VPS, RAC, VCJ); Pathology, School of Medical Sciences, Santa Casa de São Paulo, São Paulo, SP, Brazil (GP, MAS)

Recebido em 29/10/2007 Aceito em 19/8/2008 


\section{INTRODUCTION}

$\mathrm{D}$ iabetes mellitus (DM) is the main cause of nontraumatic amputations worldwide (1). DM patients have 15 times greater risk of lower extremity amputation than nondiabetic patients (2). Atherosclerotic macrovascular disease in patients with DM usually affects the infragenicular arteries (3). An arteriographic study has shown that diabetic patients have a greater prevalence of diffuse atherosclerosis simultaneously affecting the femoral, popliteal and tibial sections than nondiabetic patients (4).

Histologically, however, atherosclerotic lesions of the lower extremities seem to have the same morphology and distribution in both diabetic and nondiabetic patients. Differences are often found only in the occurrence of calcification in the media or Monckeberg's medial calcific sclerosis, which is more common in diabetic patients $(3,5)$.

Diabetes mellitus accelerates the development of macrovascular atherosclerotic complications and leads to microvascular complications such as diabetic nephropathy and retinopathy (6). However, the existence of a microvascular disease affecting the lower extremities of diabetic patients has been questioned in literature (7).

Diabetic microangiopathy is characterized by deposition of PAS positive hyaline material in arterioles and capillaries of the lower extremities. Goldenberg e cols. (8) analyzed 152 fragments of lower extremities of diabetic and nondiabetic amputated patients, for different diseases. No differences were found in the intensity of atherosclerosis between diabetic and nondiabetic individuals; however, the authors described the presence of "diabetic lesions" in arterioles and capillaries of diabetic patients, which were characterized by deposition of a periodic acid Schiff (PAS) positive material. Other studies in the literature, however, do not confirm these findings. Strandness e cols. (9), in a histological study of vessels and tissues of diabetic and nondiabetic patients found no differences in the histological presentation of the smaller arteries when the two groups were compared. Most of the studies published, however, included small samples and used tissue fragments of patients with a diagnosis of trauma, vasculitis or tumors. Therefore, it remains unclear whether the microvascular changes found in the skin fragments studied by Goldenberg e cols. (8) were secondary to severe peripheral arterial occlusive disease (PAOD) or to diabetic microangiopathy.
The objective of this study is to investigate histological differences between the atherosclerotic occlusive disease of amputated lower limbs from diabetic and nondiabetic patients, and to observe the morphological structure of arterioles and capillaries in these groups (presence of diabetic microangiopathy). We compared the degree of obstruction and the classification of the atherosclerotic lesions of below-the-knee arteries (popliteal, anterior tibial, posterior tibial, and peroneal) of amputated lower limbs to PAOD of diabetic and nondiabetic patients, and described the histopathological changes of skin arterioles and capillaries of these patients.

\section{METHODS}

Fragments of leg arteries and skin of 57 lower extremities amputated from 55 patients were examined at Santa Casa de São Paulo, Brazil, from June 2004 to June 2006.

This study included patients that had undergone above-knee amputations due to diabetic and nondiabetic severe PAOD ischemic lesions. Patients were excluded if their amputations were motivated by acute ischemia or any other disease than PAOD, like trauma and vasculitis.

Detailed patient information was recorded following a protocol. Patients were divided into two groups, diabetic and nondiabetic, for the analysis of histopathological differences in leg arteries, arterioles and capillaries. Diabetic patients were defined as those with a prior diagnosis of DM and under treatment for it.

After femoral superficial clamping, during aboveknee amputation, the arterial trifurcation was dissected, the popliteal artery were cut above the bifurcation and the proximal portion of anterior tibial, tibial-fibular trunk, posterior tibial and peroneal arteries were collected. Skin and subcutaneous tissue from the first or second toe, without gangrene, were also collected to analyze the arterioles and capillaries of the sample.

The specimens were placed in $10 \%$ formaldehyde solution. Four cross-sections of about $0.2 \mathrm{~cm}$ each were obtained from each of the arteries: popliteal artery above its bifurcation, and anterior tibial, tibial-fibular trunk, posterior tibial, and peroneal arteries below their origins. Four skin fragments were obtained from each toe and sent to paraffin blocks.

All sections were stained with hematoxylineosin (HE), PAS (Periodic Acid-Schiff) method, and Masson's trichrome. 
The samples were analyzed by blinded observers to DM diagnoses. The material was examined using an Axioskop 40 Zeiss optical microscope connected to a DSC-S85 Sony ${ }^{\circledR}$ camera (4 megapixels).

The atherosclerotic lesions of arteries in diabetic and nondiabetic patients were compared according to two parameters: degree of lumen stenosis $(\mathrm{l}=0$ to $50 \%$ stenosis; $2=50$ to $75 \%$ stenosis; and $3=$ more than $75 \%$ stenosis); and histological classification of the atherosclerotic lesions according to Stary e cols. (10). This classification describes six types of lesions: Type I: isolated macrophage foam cells; Type II: mainly intracellular lipid accumulation; Type III: pools of foam cells and small pools of extracellular lipids; Type IV: (atheroma) well-formed lipid nucleus with foam cells and extracellular deposits of lipids in the form of cholesterol crystals; Type V: (fibroatheroma) well-formed lipid nucleus covered by fibrous capsule; Type VI: plaque complications with ulceration, fissure, thrombosis, inter-plaque hemorrhage or intense calcification. For analytical purposes, the absence of atherosclerotic lesions was classified as Type 0 , usually characterized only by intimal fibrous thickening.

The arteries of the two groups were also examined to identify Monckeberg's medial calcific sclerosis and PAS-positive thickening of the arterial vasa vasorum.

Skin fragments were examined to identify capillary PAS positive thickening and fragments were classified into four categories: 0 or absent: no capillary wall thickening in the dermis (Figure 1); 1 or mild: rare capillaries with discrete PAS-positive wall thickening, scarcely distributed in the dermis (Figure 2); 2 or moderate: frequent capillaries with moderate PAS-positive wall thickening, irregularly distributed in the dermis (Figure 3); 3 or intense: capillaries with intense and diffuse PAS-positive wall thickening, homogeneously distributed in the dermis (Figure 4). The arteriolar thickening was considered present or absent.

The sample size for the comparison of capillary thickening between diabetic and nondiabetic patients was calculated using the chi-square test, considering a power of $80 \%$ and a $5 \%$ of significance level.

The chi-square and the Fisher exact tests were used to investigate the association between the histological variables and the disease (DM). Analysis of variance (ANOVA) was used to compare quantitative variables. Backward stepwise logistic regression (Wald)

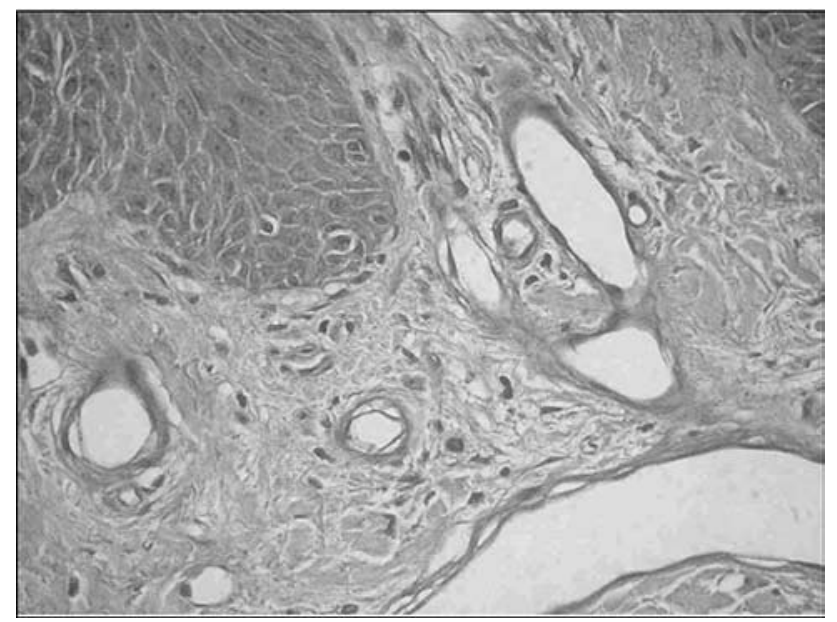

Figure 1. Skin fragment with normal capillaries, classified as 0 or no thickening $(A O: 400 x)$.

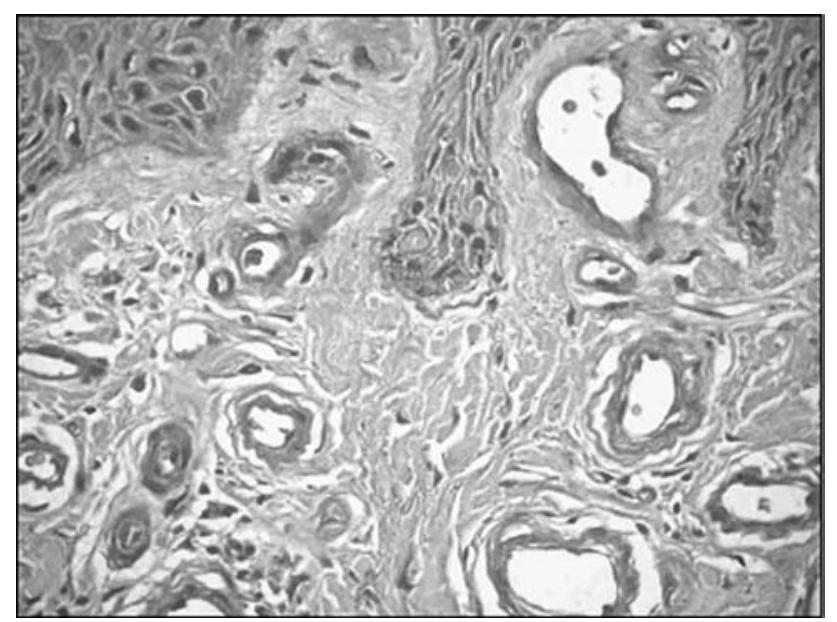

Figure 2. Skin fragment with capillaries showing thickening classified as mild or category 1 (AO:400X)

was used to calculate which of the study variables was associated with capillary thickening. A 5\% significance level ( $\mathrm{p} \leq 0.05)$ was considered in order to reject the null hypothesis.

This study was approved by the Research Ethics Committee of Santa Casa de São Paulo, São Paulo, Brazil. All patients included in the study provided informed consent.

The authors had full access to all study data and take responsibility for their integrity. All authors have read and agreed to the manuscript as written. 


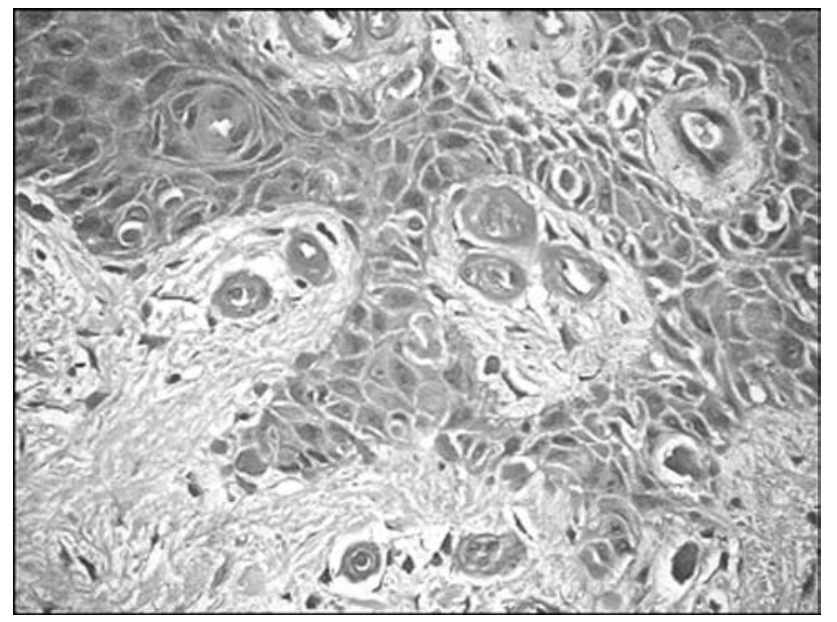

Figure 3. Skin fragment with capillaries showing PAS-positive thickening classified as moderate or category 2 (AO:400x)

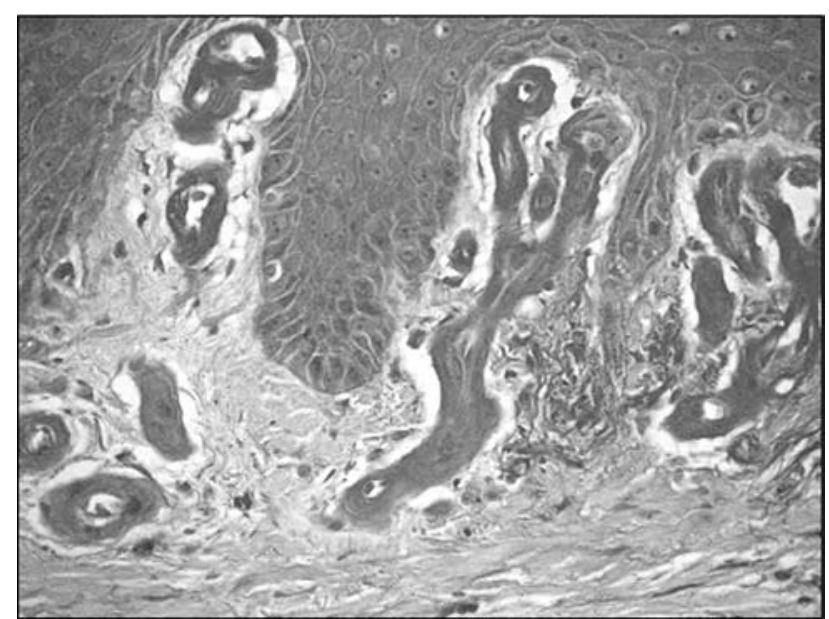

Figure 4. Skin fragment with capillaries showing PAS-positive thickening classified as intense or category 3 (AO:400x)

\section{RESULTS}

Among the 55 patients, 26 (47.3\%) had type 2 diabetes, and 29 (52.7\%) did not have diabetes; 39 (70.9\%) had hypertension. Mean age was $67.89 \pm 14.28$ years; 32 patients $(58.2 \%)$ were male, and $27(49.1 \%)$ were smokers. The clinical examination of pulses was used to classify the segment affected by PAOD: on 12 $(21.8 \%)$ patients, it was the aortoiliac segment; for 39 (70.9\%) femoral-popliteal; and for four (7.3\%), belowknee. The right lower limb was amputated in $29 \mathrm{pa}$ tients $(52.7 \%)$, the left lower limb in $24(43.7 \%)$, and bilateral amputation was performed in two patients $(3.6 \%)$ in different times. Mean age $(67.38 \pm 15.12$ vs. $68.34 \pm 13.73$ years; $\mathrm{p}=0.80)$ and initial white blood cells count $(13.362 \pm 4.801$ vs. $13.155 \pm 5.188 \mathrm{~mL} / \mathrm{u}$; $\mathrm{p}=0.87$ ) did not show statistically significant differences between diabetic and nondiabetic patients. Women were statistically more prevalent in the diabetic group $(\mathrm{p}=0.02)$ and arterial hypertension too $(\mathrm{p}=0.006)$. Smoking was significantly more prevalent among nondiabetic patients $(\mathrm{p}=0.03)$. Only patients with diabetes had kidney disease requiring dialysis $(\mathrm{p}=0.04)$. DM patients had a significantly smaller incidence of aortoiliac PAOD and a greater incidence of below-knee PAOD (with pedal pulses absent and popliteal pulses present) at physical examination $(\mathrm{p}=0.002)$. The comparison results between the two groups are shown in Table 1.

Table 1. Comparative analysis of the demographic profiles of patients with and without DM.

\begin{tabular}{|c|c|c|c|c|c|}
\hline \multirow[b]{2}{*}{ Variables } & \multicolumn{2}{|c|}{ Non-DM } & \multicolumn{2}{|c|}{ DM } & \multirow[b]{2}{*}{$p$} \\
\hline & $\mathbf{N}$ & $\%$ & $\mathbf{N}$ & $\%$ & \\
\hline Sex & & & & & 0.02 \\
\hline Male & 21 & 72.4 & 11 & 42.3 & \\
\hline Female & 8 & 27.6 & 15 & 57.7 & \\
\hline Smoker & & & & & 0.03 \\
\hline No & 11 & 37.9 & 17 & 65.4 & \\
\hline Yes & 18 & 62.1 & 9 & 34.6 & \\
\hline PAOD segment & & & & & 0.002 \\
\hline Aortoiliac & 11 & 37.9 & 1 & 3.8 & \\
\hline Femoral-popliteal & 18 & 62.1 & 21 & 80.8 & \\
\hline Below-knee & 0 & 0.0 & 4 & 15.4 & \\
\hline Hypertension & & & & & 0.006 \\
\hline No & 13 & 44.8 & 3 & 11.5 & \\
\hline Yes & 16 & 55.2 & 23 & 88.5 & \\
\hline $\begin{array}{l}\text { Kidney disease } \\
\text { requiring dialysis }\end{array}$ & & & & & 0.04 \\
\hline No & 29 & 100 & 22 & 84.6 & \\
\hline Yes & 0 & 0 & 4 & 15.4 & \\
\hline
\end{tabular}


We collected and studied 54 popliteal artery segments $(94.7 \%$ of 57 limbs), 41 anterior tibial arteries (71.9\%), 36 tibial-fibular trunks $(63.2 \%), 42$ posterior tibial arteries $(75 \%)$, and 35 of inter-bone arteries $(62.5 \%)$. There was no significant difference among the number of arteries analyzed between the two groups (diabetic and nondiabetic patients).

The comparative analysis of the atherosclerotic impairment of the below-knee arteries between the two groups is shown in Tables 2 and 3.

Table 2. Comparative analysis of percentage of lumen stenosis in five types of below-knee arteries between patients with and without DM.

\begin{tabular}{|c|c|c|c|c|c|}
\hline \multirow[b]{2}{*}{ \% stenosis } & \multicolumn{2}{|c|}{ Non-DM } & \multicolumn{2}{|c|}{ DM } & \multirow[b]{2}{*}{$p$} \\
\hline & $\mathbf{N}$ & $\%$ & $\mathbf{N}$ & $\%$ & \\
\hline Popliteal artery & & & & & 0.53 \\
\hline 1 & 8 & 28.6 & 10 & 40.0 & \\
\hline 2 & 9 & 32.1 & 5 & 20.0 & \\
\hline 3 & 11 & 39.3 & 10 & 40.0 & \\
\hline Anterior tibial artery & & & & & 0.90 \\
\hline 1 & 5 & 27.8 & 7 & 30.4 & \\
\hline 2 & 3 & 16.7 & 3 & 13.0 & \\
\hline 3 & 10 & 55.5 & 13 & 56.6 & \\
\hline Tibial-fibular trunk & & & & & 0.16 \\
\hline 1 & 1 & 5.6 & 4 & 22.2 & \\
\hline 2 & 4 & 22.2 & 1 & 5.6 & \\
\hline 3 & 13 & 72.2 & 13 & 72.2 & \\
\hline Posterior tibial artery & & & & & 0.75 \\
\hline 1 & 2 & 10.5 & 2 & 8.7 & \\
\hline 2 & 4 & 21.1 & 3 & 13.0 & \\
\hline 3 & 13 & 68.4 & 18 & 78.3 & \\
\hline Peroneal artery & & & & & 0.78 \\
\hline 1 & 5 & 31.2 & 4 & 21.1 & \\
\hline 2 & 3 & 18.8 & 4 & 21.1 & \\
\hline 3 & 8 & 50.0 & 11 & 57.8 & \\
\hline
\end{tabular}

DM=diabetes mellitus; $1=0$ to $50 \%$ stenosis; $2=50$ to $75 \%$ stenosis; $3=$ more than $75 \%$ stenosis.
Table 3. Comparative analysis of histological classification of atherosclerotic lesions in below-knee arteries in patients with and without DM.

\begin{tabular}{|c|c|c|c|c|c|}
\hline \multirow{2}{*}{$\begin{array}{l}\text { Histological } \\
\text { classification of } \\
\text { atherosclerotic lesion }\end{array}$} & \multicolumn{2}{|c|}{ Non-DM } & \multicolumn{2}{|c|}{ DM } & \multirow[b]{2}{*}{$\mathbf{p}$} \\
\hline & $\mathbf{N}$ & $\%$ & $\mathbf{N}$ & $\%$ & \\
\hline Popliteal artery & & & & & 0.91 \\
\hline 0 & 3 & 10.7 & 3 & 11.3 & \\
\hline Type IV & 2 & 7.1 & 1 & 5.7 & \\
\hline Type V & 8 & 28.6 & 8 & 30.2 & \\
\hline Type VI & 15 & 53.6 & 13 & 52.8 & \\
\hline Anterior tibial artery & & & & & 0.51 \\
\hline 0 & 4 & 22.2 & 3 & 13.0 & \\
\hline Type IV & 0 & 0.0 & 2 & 8.7 & \\
\hline Type V & 5 & 27.8 & 5 & 21.7 & \\
\hline Type VI & 9 & 50.0 & 13 & 56.6 & \\
\hline Tibial-fibular trunk & & & & & 0.48 \\
\hline 0 & 1 & 5.6 & 1 & 5.6 & \\
\hline Type IV & 0 & 0.0 & 1 & 5.6 & \\
\hline Type V & 5 & 27.8 & 2 & 11.1 & \\
\hline Type VI & 12 & 66.6 & 14 & 77.7 & \\
\hline Posterior tibial artery & & & & & 0.70 \\
\hline 0 & 4 & 21.1 & 4 & 17.4 & \\
\hline Type V & 4 & 21.1 & 3 & 13.0 & \\
\hline Type VI & 11 & 57.8 & 16 & 69.6 & \\
\hline Peroneal artery & & & & & 0.97 \\
\hline 0 & 3 & 18.8 & 4 & 21.1 & \\
\hline Type V & 2 & 12.5 & 2 & 10.5 & \\
\hline Type VI & 11 & 68.7 & 13 & 68.4 & \\
\hline
\end{tabular}

$\mathrm{DM}=$ diabetes mellitus.

The histopathological study of the popliteal artery segments showed that the percentage of lumen obstruction and the type of atherosclerotic lesion did not differ between groups. However, diabetic patients had a statistically higher prevalence of thickening of the vasa-vasorum $(55.6 \%$ vs. $33.3 \%, \mathrm{p}=0.04)$ and of Monckeberg's medial calcific sclerosis $(61.8$ vs. $38.9 \%, \mathrm{p}=0.01)$. 
The distribution of variables studied for the anterior tibial artery, the tibial-fibular trunk and the peroneal artery did not show significant differences between the two groups either.

The percentage of obstruction, classification of the atherosclerotic lesion and thickening of the vasa-vasorum of the posterior tibial artery was similar in both groups, and the only difference found was the greater prevalence of Monckeberg's medial calcific sclerosis among diabetic patients ( 47.8 vs. $15.8 \%, \mathrm{p}=0.02$ ).

No significant differences were found in the percentage of arterial obstruction or classification of atherosclerotic lesions in the analysis of the 208 below-knee arteries of diabetic and nondiabetic patients with severe lower extremity PAOD (Tables 2 and 3). Most diabetic and nondiabetic patients had advanced atherosclerotic lesions, types V and VI, in the below-knee arteries.

Fifty-three skin fragments were analyzed (93\% of the 57 fragments of amputated toes). Histological analysis of the other 4 fragments was not possible due to extensive tissue necrosis. The analysis of the arterioles did not show any significant differences related to the presence of thickening between the two groups ( $63 \%$ vs. $50 \%$; $=0,25)$.

Diabetic patients showed a significantly greater occurrence $(\mathrm{p}=0.03)$ of moderate and intense PASpositive capillary thickening than nondiabetic patients (Table 4 ). Other variables did not show statistic correlation with capillary thickening: $28 \%$ of hypertensive patients had moderate and $18 \%$ had intense capillary wall thickening, contrasting with $14 \%$ and $21 \%$ of patients with normal blood pressure $(p=0,4)$. $21 \%$ of smokers had moderate and $21 \%$ had intense capillary wall thickening, contrasting with $28 \%$ and $17 \%$ of non-smokers $(\mathrm{p}=0,9) .25 \%$ of women and $24 \%$ of men had moderate, and $29 \%$ of women and $10 \%$ of men had intense capillary wall thickening $(p=0,2)$. All women were post-menopausal and none used hormonal replacement therapy. Logistic regression showed that only DM was significantly associated with moderate or severe capillary wall thickening $(p=0.005)$, whereas no association was found on the other variables (sex, smoking, segment affected by PAOD, kidney disease requiring dialysis, and hypertension). Patients with diabetes had a 5.7 (odds ratio) greater chance (95\% CI: 1.7-18.8) of having moderate or severe PAS-positive capillary thickening than patients without diabetes.
Table 4. Comparative analysis of PAS-positive thickening of capillary walls in patients with and without DM.

\begin{tabular}{lcccccc}
\hline & Non-DM & \multicolumn{4}{c}{ DM } \\
$\begin{array}{l}\text { Capillary wall } \\
\text { thickening }\end{array}$ & $\mathbf{N}$ & $\%$ & $\mathbf{N}$ & $\%$ & $\mathbf{p}$ \\
\hline 0 & 8 & 30.8 & 4 & 14.8 & \\
\hline 1 & 12 & 46.2 & 6 & 22.2 & \\
\hline 2 & 3 & 11.5 & 10 & 37 & \\
\hline 3 & 3 & 11.5 & 7 & 26 & 0.033 \\
\hline
\end{tabular}

$\mathrm{DM}=$ diabetes mellitus.

\section{DIscussion}

The mean age of our patients was over 60 years and did not differ between groups. This is in agreement with the literature and with previous findings by our group (11-17). We believe that, even though PAOD occurs sooner in diabetic patients than in patients without diabetes $(6,7,18)$, the disease in advanced form, which results in critical ischemia and greater rates of amputation, occurs at a later age after a long period of disease, as in nondiabetic patients.

Women were statistically more prevalent in the group of diabetic patients. Other authors also found a larger number of women among their diabetic patients with critical ischemia who underwent amputations (19$21)$. This finding may be associated with the reported in coronary atherosclerotic disease studies, which have shown that the protective effect of the female sex is eliminated by diabetes, and that diabetes doubles the risk of cardiovascular disease in men and triples it in women $(22,23)$.

The arterial segment affected by PAOD diagnosed by pulses physical examination showed that most patients in both groups had femoral-popliteal disease. DM patients had significantly less aortoiliac disease and a greater incidence of impairment of the below-knee segment, which is in agreement with findings reported in the literature $(3,7,24,25)$.

The purpose of comparing percentage of arterial stenosis in legs from the two groups was to determine if a possible difference in severity of arterial obstruction could explain any changes in the morphology of foot capillaries (capillary thickening). The study of Goldenberg e cols. (8) described morphological changes in ar- 
terioles and capillaries of diabetic patients, called "small vessel disease". However they used a heterogeneous nondiabetic control group with patients amputated for different diseases including trauma, which brought up the question if those capillary thickening they found could be secondary only to severe atherosclerotic macrovascular disease in leg arteries of diabetic patients.

Nevertheless, in our sample, no histological differences were found between diabetic and nondiabetic patients in percentage of obstruction of the below-knee arteries (popliteal, anterior tibial, tibial-fibular trunk, posterior tibial, or peroneal), which is in agreement with findings by Conrad (26), and Ferrier (27), but differs from those reported by Strandness e cols. (9), who found a greater percentage of trifurcation disease in the legs of diabetic patients (9). Arteriographic study also showed greater prevalence of infrapopliteal disease in diabetic patients (4).

In our study the most prevalent degree of obstruction was greater than $75 \%$ in infra-popliteal arteries studied in diabetic and nondiabetic patients, which showed that advanced PAOD and ischemia were present in all patients of our sample. However, the arteries were not examined along the entire leg but only close to their origin, which is the segment where atherosclerotic lesions tend to be more severe (close to the bifurcations). The arteriogram - not analized in this work - provided a guide to the sites of obstruction but do not show the characteristics of the atherosclerotic plaque surface accurately, and may also fail to detect plaques, because of the technique used for examination or due to the presence of lesions that do not cause significant stenosis (10).

The histological classification of the atherosclerotic lesions also demonstrated the severity of peripheral atherosclerotic disease in our patients. We used the histological classification of advanced atherosclerotic lesions proposed by Stary e cols. (10) in 1995 to classify the severity of the disease. Types IV, V, and VI, the predominant types in our two groups, are advanced lesions that occlude the arterial lumen and cause symptoms, but may fail to be detected by angiography. However, type VI atherosclerotic plaques or complicated lesions are associated with symptoms of arterial obstruction, fissures, ulceration, hemorrhage and greater thrombosis. Our diabetic and nondiabetic patients had a predominance of type VI atherosclerotic lesions in all five types of arteries studied (popliteal and trifurcation of the leg). We did not find this comparison in other studies.
The calcification of the medial layer or Monckeberg's sclerosis, a characteristic of diabetes, was more prevalent in patients with DM as previously reported, but was not exclusive of this group $(3,27)$. This difference was statistically significant in the comparisons of the popliteal and posterior tibial arteries, for which we had a larger sample. However, the examination of the anterior tibial and the tibial-fibular trunk also showed that the calcification of the medial layer was more prevalent among diabetic patients, although this difference was not statistically significant.

A statistically greater prevalence of thickening of the vasa-vasorum in the arterial adventitia in the DM groups was found only in the popliteal artery, in agreement with findings by Goldenberg e cols. (8). This may be due to the fact that the popliteal artery was the largest sample in our study. The percentage of patients without vasa-vasorum thickening of the posterior tibial, anterior tibial and peroneal arteries was greater than the percentage of patients with thickening, even in the DM group. Therefore, we believe that there is no specific diabetic pattern of vasa-vasorum thickening in adventicia.

A greater occurrence of PAS-positive thickening of the skin's capillaries was found among diabetic patients (63\% moderate or intense capillary thickening in DM patients vs. $23 \%$ moderate or intense capillary thickening in nondiabetic; $\mathrm{p}=0,003$ ), which confirmed the presence of peripheral diabetic microangiopathy. Goldenberg e cols. (8) called "lesion of small vessels" due to the accumulation of PAS-positive hyaline material in the arterioles and capillaries was followed by other studies similar to ours, which confirmed the existence of peripheral diabetic microangiopathy, such as those that occur in the kidneys and the retina (28-33). Other authors, however, deny the occurrence of a peripheral microvascular disease in diabetes $(6,7,9,26,27,34,35)$. Ferrier (27) studied arteries of lower extremities amputated from 20 patients ( 10 diabetic and 10 nondiabetic) and found no statistical differences in the frequency of arterial obstruction between the two groups, although calcification of the medial layer was greater in diabetic patients. Moreover, they found no specific lesion with thickening of arterioles and capillaries in the diabetic patients. Conrad e cols. (26) studied arteries of lower extremities amputated from 20 patients (10 diabetic and 10 nondiabetic) and found no differences between the pattern and the length of occlusion of leg arteries and no significant differences in the degree of occlusion of the small vessels of the skin and muscle between the two groups. 
Results of logistic regression showed that only DM was significantly associated with moderate or severe capillary thickening and ruled out hypertension, sex, segment affected by PAOD and chronic kidney disease as confounding variables. In agreement with other studies, we found no correlation between hypertension and capillary wall thickening $(8,26,36)$. Hypertension, however, is frequently associated with microvascular complications of diabetes, such as retinopathy and nephropathy (37), which raises the hypothesis that it may be also associated with DM in the progression of peripheral microangiopathy. Analyzing only the nondiabetic group, $13 \%$ of the hypertensive patients had intense capillary thickening, while $9 \%$ of the normal blood pressure patients had intense capillary wall thickening, a difference without statistic significance. Three diabetic patients with normal levels of blood pressure had capillary wall thickening: two in intense category and one in moderate, confirming the role of diabetes in PAS positive capillary wall thickening.

Our study, however, differs from previous investigations because all patients have severe ischemia and histological qualitative study of severity of PAOD, it included a larger number of patients and obtained all samples of skin capillaries from amputations performed at the same level (above-knee). Our findings confirmed the presence of peripheral diabetic microangiopathy, but we may not forget that capillary thickening has been observed in some nondiabetic patients too. Aagenaes and Moe (36) and Banson and Lacy (28) showed that capillary thickening was not uniform in distribution, and found capillaries with and without wall thickening in the same samples. We included all capillaries of the sample in our capillary thickening classification (absent, mild, moderate or intense).

Although we found that there is a pattern of capillary changes more frequent in diabetic than in nondiabetic patients, it does not justify maintaining an ischemic limb when there is the possibility of revascularization, but this may be the explanation for the unfavorable evolution of some patients. Other studies in literature have already demonstrated that, although the opportunity of undergoing arterial reconstruction is lower in diabetic patients, the results of infrainguinal revascularization are similar for diabetic individuals and other patients with PAOD $(3,38)$. Further studies are needed before diabetic peripheral microangiopathy can be totally understood.

Based on the results taken, we conclude that there are no differences in the degree of stenosis or histologi- cal classification of atherosclerotic lesions in below-knee arteries between diabetic and nondiabetic patients with advanced PAOD and critical ischemia. Diabetic patients show a PAS-positive capillary thickening that is more intense and diffuse than in nondiabetic patients.

Acknowledgment. We are grateful to the Support Center for Scientific Publications of Santa Casa de São Paulo - Faculty of Medical Sciences for the editorial assistance. No potencial conflict of interest relevant to this article was reported.

\section{REFERENCES}

1. Slovenkai MP. Foot problems in diabetes. Med Clin North Am. 1998;82:9948-70.

2. Most RS, Sinnock F. The epidemiology of lower extremity amputations in diabetic individuals. Diabetes Care. 1983; 6:87-91.

3. Mueller MP, Wright J, Klein SR. Diabetes and peripheral vascular disease. In: Veith FJ, Hobson RW, Williams RA, Wilson $\mathrm{S}$, editors. Vascular surgery: principles and practice. 2. ed. New York: McGraw Hill; 1994. p. 514-22.

4. Gensler SW, Haimovici H, Hoffert P, Steinman C, Beneventano TC. Study of vascular lesions in diabetic, nondiabetic patients. Arch Surg. 1965;91:617-22.

5. Colwell JA, Lopes-Virella M, Halushka PV. Pathogenesis of atherosclerosis in diabetes mellitus. Diabetes Care. 1981; 4:121-33.

6. Drouet L. Atherothrombosis in diabetes - its evolution and management. Diabetes Obes Metab. 1999;1:37-47.

7. Lo Gerfo FW, Coffman JD. Vascular and microvascular disease of the foot in diabetes: implications for foot care. N Engl J Med. 1984;311:1615-9.

8. Goldenberg S, Alex M, Joshi RA, Blumenthal HT. Nonatheromatous peripheral vascular disease of the lower extremity in diabetes mellitus. Diabetes. 1959;8:261-73.

9. Strandness Jr. DE, Priest RE, Gibbons GE. Combined clinical and pathologic study of diabetic and nondiabetic peripheral arterial disease. Diabetes. 1964;13:366-72.

10. Stary HC, Chandler AB, Dinsmore RE, Fuster V, Glagov S, Insull Jr W, et al. A definition of advanced types of atherosclerotic lesions and a histological classification of atherosclerosis. A report from the Committee on Vascular Lesions of the Council on Arteriosclerosis, American Heart Association. Circulation. 1995;92:1355-74.

11. Loue TJ, Bartlett JG, Tally FP, Gorbach SL. Aerobic and anaerobic bacteria in diabetic foot ulcers. Ann Intern Med. 1976;85:461-3.

12. Sharp CS, Bessman AN, Wagner Jr FW, Garland D, Reece E. Microbiology of superficial and deep tissues in infected diabetic gangrene. Surg Gynecol Obstet. 1979;149:217-9.

13. Nicholas GG, Myers JL, Demuth WE. The role of vascular laboratory criteria in the selection of patients for lower extremity amputation. Ann Surg. 1982;195:469-73.

14. Pittet D, Wyssa B, Herter-Clavel C, Kursteiner K, Vaucher J, Lew PD. Outcome of diabetic foot infections treated conservatively. Arch Intern Med. 1999;159:851-6.

15. Gamba MA, Oliveira O, Fadlo Filho F, Martinez C, Kajita MY. A magnitude das alterações cutâneas, neurológicas, vascula- 
res de extremidades inferiores de pessoas com diagnóstico de diabetes mellitus - campanha da detecção e educação da ANAD. Diabetes Clinica. 2001;6:414-8.

16. Adler Al, Stevens RJ, Neil A, Stratton IM, Boulton AJM, Holman RR. UKPDS 59: hyperglycemia and other potentially modifiable risk factors for peripheral vascular disease in type 2 diabetes. Diabetes Care. 2002;25:894-9.

17. Santos VP, Silveira DR, Caffaro RA. Risk factors for primary major amputation in diabetic patients. Sao Paulo Med J. 2006; 124:66-70.

18. Pratt TC. Gangrene and infection in the diabetics. Med Clin North Am. 1965;49:987-1004.

19. Cameron HC, Leonard J, Robinson MP. Amputations in the diabetic: outcome and survival. Lancet. 1964;2:605-7.

20. Lange E. Current surgery: drug combination treatment of diabetic gangrene of the foot. Infection. 1991;19:S351-4.

21. Lira JRS, Castro AA, Pitta GBB, Figueiredo LFP, Lage VMM, Miranda Jr F. Prevalence of sensorimotor polyneuropathy in the feet at the moment of diabetes mellitus diagnosis. J Vasc Bras. 2005;4:22-6.

22. Nathan DM. Long-term complications of diabetes mellitus. $\mathrm{N}$ Engl J Med. 1993;328:1676-84.

23. Kannel WB, Daniel LM. Diabetes and cardiovascular disease: the Framinghan Study. JAMA. 1979;241:2035-8.

24. Caputo GM, Cavanagh PR, Ulbrecht JS, Gibbons GW, Karchmer AW. Assessment and management of foot disease in patients with diabetes. N Engl J Med 1994;331:854-60.

25. Faglia E, Favales F, Quarantiello A, Calia P, Clelia P, Brambilla $G$, et al. Angiographic evaluation of peripheral arterial occlusive disease and its role as a prognostic determinant for major amputation in diabetic subjects with foot ulcers. Diabetes Care. 1998;21:625-30.

26. Conrad MC. Large and small artery occlusion in diabetics and nondiabetics with severe vascular disease. Circulation. 1967;36:83-91.

27. Ferrier TM. Comparative study of arterial disease in amputated lower limbs from diabetics and non-diabetics (with special reference to feet arteries). Med J Aust. 1967;1:5-11.
28. Banson BB, Lacy PE. Diabetic microangiopathy in human toes - with emphasis on the ultrastructural change in dermal capillaries. Am J Pathol. 1964;45:41-58.

29. McMillan DE. Deterioration of the microcirculation in diabetes. Diabetes. 1975;24:944-57.

30. Raskin P, Pietri AO, Unger R, Shannon A. The effect of diabetic control on the width of skeletal-muscle capillary basement membrane in patients with type I diabetes mellitus. N Engl J Med. 1983;25:1546-50.

31. Camerini-Davalos RA, Velasco C, Glasser M, Bloodworth Jr JMB. Drug-induced reversal of early diabetic microangiopathy. N Engl J Med. 1983;25:1551-6.

32. Tilton RG, Faller AM, Burkhardt JK, Hoffmann PL, Kilo C, Williamson JR. Pericyte degeneration and acellular capillaries are increased in the feet of human diabetic patients. Diabetologia. 1985;28:895-900.

33. Zatz R, Brenner BM. Pathogenesis of diabetic microangiopathy - the haemodynamic view. Am J Med. 1986;80:443-53.

34. Dinh TL, Veves A. Microcirculation in the diabetic foot: an update. Int J Low Extrem Wounds. 2004;3:60-1.

35. Friederici HHR, Tucker R, Schwartz TB. Observations on small blood vessels of skin in the normal and diabetic patients. Diabetes. 1960;15:233-50.

36. Aagenaes $\mathrm{O}$, Moe $\mathrm{H}$. Light and electron microscopic study of skin capillaries of diabetics. Diabetes 1961;10:253-9.

37. Neely KA, Quillen DA, Schachat AP, Gardner TW, Blankenship GW. Retinopatia diabética. Clin Med Am Norte. 1998;4:195-226.

38. Fratezi AC, Albers M, De Luccia ND, Pereira CA. Outcome and quality of life of patients with severe chronic limb ischaemia: a cohort study on the influence of diabetes. Eur J Vasc Endovasc Surg. 1995;10:459-65.

\section{Correspondence to:}

Vanessa Prado dos Santos

Av. Garibaldi, 1.477, sala 305,

40170-130 Salvador, BA

E-mail:vansanbr@hotmail.com 